\title{
Ergonomics Simulation and Analysis of Specially Designed Chair
}

\author{
Shahrol Mohamaddan ${ }^{1,2}$, Aliff Rahman ${ }^{1}$, Musdi Shanat ${ }^{3}$, Siti Zawiah Md Dawal ${ }^{4}$, Akihiko Hanafusa ${ }^{2}$ \\ ${ }^{1}$ Faculty of Engineering, Universiti Malaysia Sarawak, \\ 94300 Kota Samarahan, Sarawak, Malaysia \\ ${ }^{2}$ College of Systems Engineering and Science, Shibaura Institute of Technology, \\ Fukasaku 307, Minuma-ku, 337-8570 Saitama, Japan \\ ${ }^{3}$ Faculty of Applied and Creative Arts, Universiti Malaysia Sarawak, \\ 94300 Kota Samarahan, Sarawak, Malaysia \\ ${ }^{4}$ Faculty of Engineering, University of Malaya, \\ 50603 Kuala Lumpur, Malaysia
}

Received: August 3, 2021. Revised: November 20, 2021. Accepted: December 1, 2021. Published: December 31, 2021.

\begin{abstract}
Chair comes in different sizes and shapes depending on the functions as well as the users involved. However, the designers seldom consider the ergonomics aspect in chair design. This research has been conducted as a case study to compare and select the best design parameters within two chairs known as Chair A and B using human modelling software called AnyBody. Different parameter was manipulated in the simulation which is backrest angles for Chair $A$ and seat heights for Chair B. A total of ten chairs with different parameters (five from Chair A and five from Chair B) were conducted in the simulation. Results were generated through inverse dynamics analysis in the form of muscle activities envelopes and reaction force on vertebrae $L 4$ to $L 5$. The result shows that $80^{\circ}$ backrest was the best ergonomics design for Chair A while $0.30 \mathrm{~m}$ seat height was the best ergonomics design for Chair $B$. The simulation conducted is important as an early ergonomics intervention before the real chair fabrication is conducted.
\end{abstract}

Keywords-Anybody, Chair design, Ergonomics, Muscles.

\section{INTRODUCTION}

$\mathrm{T}$ HE goal of ergonomics is to fit the task to the individual, not the individual to the task [1]. Ergonomics knowledge is useful in the industrial design application. It is important to cope with variations between humans with the aim to optimize products comfort, safety, and functionality [2]. Anthropometry is the measurement of human body using bony landmarks where heights, breadths, depths, distances, circumferences, and curvatures are measured. Anthropometry is used as a reference in designing tools, machines, systems, and workplaces to give comfort to the users. However, in the creative design, the data from anthropometry measurement is occasionally neglected in the product development. For example, in chair design the main consideration is only on the 'beauty' or the 'ecstatic' elements that compromised the humans as the main users.

Chair design is closely related to ergonomics as data from anthropometry measurement is used during the designing process. Although sitting is good for the body, a bad sitting posture can be a habit and over time may cause Work-related Musculoskeletal Disorders (WMSDs) such as low back pain (LBP) [3]. WMSDs is the conditions where the human undergo fatigue and discomfort at their body parts [4]. A WMSDs is dependent on the task, type of contraction, intensity, duration, human capabilities, and workplace conditions [5]. A WMSDs injuries are highly prevalent in the healthcare professional [6].

Proper sitting posture is essential for preventing LBP hence it is encouraging to have a design with an upright sitting posture, maintaining right angles at the hips, ankles, knees, and elbows [7]. The seat width, seat depth, lumbar depth, lumbar height, back height, seated elbow height and popliteal height are the important anthropometric dimensions in chair design [8]. Matching the equipment such as chair and work element like siting with the capabilities of user is necessary to get optimum performance of any human-equipment systems [9].

[10] had conducted ergonomics study by using ADAMS Software and the scope of study was on vertebrae Level 1 to Level 5 (L1 to L5). It was found that prolonged sitting can exposed the human to LBP of increased intradiscal pressure that can lead to insufficient nutrition of the intervertebral disc. Leaning forward during sitting can have higher intradiscal pressure compared to relax sitting. Backrest angle is important in eliminating the lumbar lordosis. The direction of backrest and seat tilt was strongly affecting the lumbar lordosis while 
backrest height adjustment has minimum effect on synchro mechanism.

Other than backrest, research on differences in office chair controls in relation to tasks was conducted by [11]. After 30 subjects were placed in a test, it was found out that $70 \%$ of the test subject preferred larger range of backrest motion for nonVDU (Visual Display Unit). The priority of chair design differences was for comfort, time for adjustment and backrest angle of comfort. It is also found out that there was no difference between comfortable and uncomfortable seat pan, first impressions as well as maximum interface pressure.

[12] conducted research on ergonomics study of seated human by using static contact sensors and questionnaires. The study was to investigate the interface pressure distribution and time utilized for chair adjustment. The researchers found out that end-user's opportunity to test the chair for a period is important to evaluate the design aspects and not only by looking at the chair.

[13] conducted a study on anthropometric considerations for tractor seat design for a male tractor driver. The objective was to identify anthropometry measurements needed in designing the seat for the tractor driver. It was found that there were 11 measurements needed for designing the tractor seat which consists of height, pan width, length, backrest width, backrest height, backrest inclination, pan tilt, pan concavity, backrest concavity, cushion, and adjustments. It was concluded that comfort is the major goal for considering anthropometric in designing the seat. Similar research on chair designing was also conducted by [14]. The researchers stated that not only the measurement of the chair should be taken into consideration, the materials used should also be included in designing ergonomic chair.

The objective of this study is to apply an ergonomics software known as AnyBody [15] as an early ergonomics intervention for good chair design using simulation method. The focus is on the muscle activities envelope and vertebrae L4 to L5 reaction forces analysis. Since the research related to ergonomics simulation is considered limited, the early intervention using software analysis can avoid injuries to the user and at the same time provide an optimum comfort for new product development. A case study of human model sitting on two different chairs design with example of manipulated parameters named as Chair A and B was conducted. With the results obtained, the best chair was chosen and suggestions for improvement for future works were recommended at the end of the research.

\section{Methodology}

\section{A. Chairs Design}

The research work was solely based on software simulation. Computer aided design (CAD) software was used to design the two different chairs: Chair A and B. The two chairs were designed as a case study for this research based on real world observation. Chair A is designed with different backrest angles while Chair B is designed with different seat heights as shown in Figure 1. The specifications for both chairs are shown in Table 1.
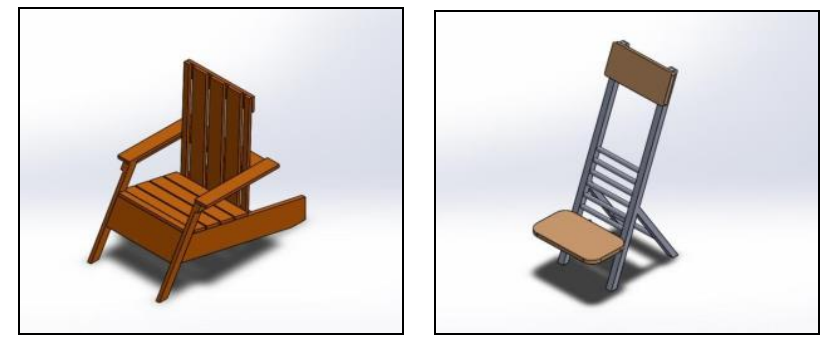

Figure 1. Design of Chair A (left) and Chair B (right)

The chair design needs to be saved as the STL files before transferring it into the AnyBody software modelling by using Environment.any file. In this file, adjustment of the chair was made based on the standing position of the human model. Reference frame was loaded into the model to aid in controlling the coordinate of the chair in the space.

Table 1. Chair specifications

\begin{tabular}{|c|c|c|}
\hline Specification & Chair A & Chair B \\
\hline Seat width & $0.05 \mathrm{~m}$ & $0.36 \mathrm{~m}$ \\
\hline Seat length & $0.48 \mathrm{~m}$ & $0.21 \mathrm{~m}$ \\
\hline Seat height & $0.33 \mathrm{~m}$ & $\begin{array}{c}0.20 \mathrm{~m}, 0.25 \mathrm{~m}, \\
0.30 \mathrm{~m}, 0.35 \mathrm{~m}, \\
0.40 \mathrm{~m}\end{array}$ \\
\hline Seat angle & $12^{\circ}$ & $0^{\circ}$ \\
\hline Back length & $0.75 \mathrm{~m}$ & $0.80 \mathrm{~m}$ \\
\hline $\begin{array}{c}\text { Backrest angles } \\
\text { Seated elbow } \\
\text { height }\end{array}$ & $\begin{array}{c}80^{\circ}, 85^{\circ}, 90^{\circ}, 95^{\circ}, \\
100^{\circ}\end{array}$ & $110^{\circ}$ \\
\hline
\end{tabular}

\section{B. Perform the Seating Movement}

The initial position of the human model was adjusted in the Mannequin.any file. The human model selected in the software was closely similar to the Malaysian human anthropometric in [16]. The initial position was changed by changing the position of the pelvis with respect to the global reference frame created in the Environment.any file. The human model for this project was moved from a standing position to a seating position in the respective chairs.

Table 2. Joint and range motion of human body areas in Chair A (manipulated backrest angle)

\begin{tabular}{|c|c|c|c|}
\hline \multirow{2}{*}{$\begin{array}{c}\text { Backrest } \\
\text { angle }\end{array}$} & \multicolumn{3}{|c|}{ Body areas } \\
\cline { 2 - 4 } & Knee & Hip & Elbow \\
\hline $80^{\circ}$ & Flexion $70^{\circ}$ & Flexion $86^{\circ}$ & Flexion $70^{\circ}$ \\
\hline $85^{\circ}$ & Flexion $70^{\circ}$ & Flexion $80^{\circ}$ & Flexion $60^{\circ}$ \\
\hline $90^{\circ}$ & Flexion $70^{\circ}$ & Flexion $74^{\circ}$ & Flexion $55^{\circ}$ \\
\hline $95^{\circ}$ & Flexion $70^{\circ}$ & Flexion $68^{\circ}$ & Flexion $50^{\circ}$ \\
\hline $100^{\circ}$ & Flexion $70^{\circ}$ & Flexion $62^{\circ}$ & Flexion $48^{\circ}$ \\
\hline
\end{tabular}

The distance of the foot apart was constant for all chairs, but the motions were different since the chairs are having different designs. There were a few movements involved in modelling 
the human model to sit on the chairs. The movements for both Chair A and Chair B are shown in the Table 2 and 3 below. The value was taken based on sitting postures within the simulation environment in the software.

Table 3. Joint and range motion of body areas in Chair B (manipulated seat heights)

\begin{tabular}{|c|c|c|c|}
\hline \multirow{2}{*}{$\begin{array}{c}\text { Seat } \\
\text { heights }\end{array}$} & \multicolumn{3}{|c|}{ Body areas } \\
\cline { 2 - 4 } & Knee & Hip & Elbow \\
\hline $0.20 \mathrm{~m}$ & Flexion $104^{\circ}$ & Flexion $93^{\circ}$ & Flexion $20^{\circ}$ \\
\hline $0.25 \mathrm{~m}$ & Flexion $96^{\circ}$ & Flexion $86^{\circ}$ & Flexion $20^{\circ}$ \\
\hline $0.30 \mathrm{~m}$ & Flexion $88^{\circ}$ & Flexion $80^{\circ}$ & Flexion $20^{\circ}$ \\
\hline $0.35 \mathrm{~m}$ & Flexion $80^{\circ}$ & Flexion $70^{\circ}$ & Flexion $20^{\circ}$ \\
\hline $0.40 \mathrm{~m}$ & Flexion $73^{\circ}$ & Flexion $60^{\circ}$ & Flexion $20^{\circ}$ \\
\hline
\end{tabular}

Knee movement was made for the human model to bend towards the chair while sitting. For Chair A, the knee rotated about $70^{\circ}$; enough for the human to sit on the chair. Notice that this value is the same for all Chair A since the seat height remains constant. However, for Chair B the knee rotation is different for different chair heights. Hip movement was made to ensure the trunk of the human model touches the back of the seat for leaning. Elbow movement was adjusted for the arms of the human model to touch the hand rest of the chair. Elbow movement for Chair B was the same for all chair heights since the chair was made with no hand rest.

\section{Simulation Analysis}

The last step taken to produce the simulation of the human model from standing to sitting was through inverse dynamic analysis. For this research, the analyses were made on four areas which are the trunk muscle activity envelope, arm shoulder muscle activity envelope, leg muscle activity envelope and vertebrae L4 to L5 reaction force. Muscle activity envelope was selected from this analysis because it is an important parameter to optimize ergonomics design. As an early ergonomics intervention, the results from muscle activity envelope and vertebrae L4 to L5 can be used to analyze the different design parameter used in the simulation.

\section{RESULTS AND DISCUSSION}

AnyBody software simulations were performed on human model for Chairs A and B from standing to seating position. The movement of the human model for Chair A is shown in Figure 2. Both human legs were rooted to the ground with the same spacing and level between them. Figure 3 shows the graph of muscle activity envelope for Chair A. The trend of the muscle activity envelope increases as the backrest angle increases. This happens as muscles need to do work to initiate movements and to complete the desired activity (seating in this case). By comparing the results of $80^{\circ}$ and $100^{\circ}$, there is a huge difference in the trunk muscle activities for these two chairs with both having average trunk muscle activity envelope of $1.07 \times 10-1 \%$ and $1.71 \times 10-1 \%$ respectively.
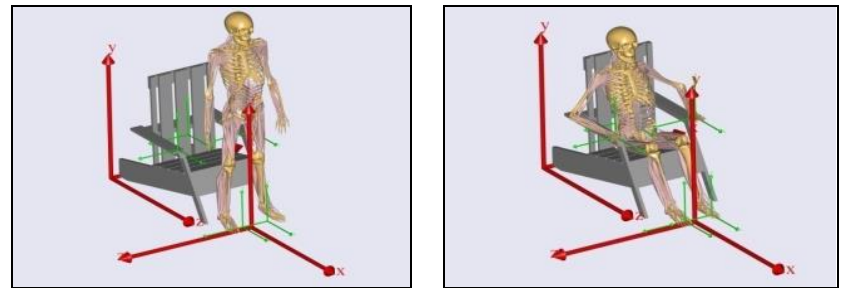

Figure 2. Initial (left) and final (right) sitting position for Chair A

The result shows that the human model needs to lean backward more for $100^{\circ}$ chair compared to $80^{\circ}$ chair and therefore extra effort is needed. The graph of shoulder arm muscle activity envelope is also showing an increasing trend with the increment of backrest angle as $80^{\circ}$ chair recorded the lowest average shoulder arm muscle activity envelope of 9.33 $\times 10-2 \%$ while the highest is $1.43 \times 10-1 \%$ for $100^{\circ}$ Chair A. However, graph of leg muscle activity envelope is showing a very small muscle activity envelope compared to other muscles.

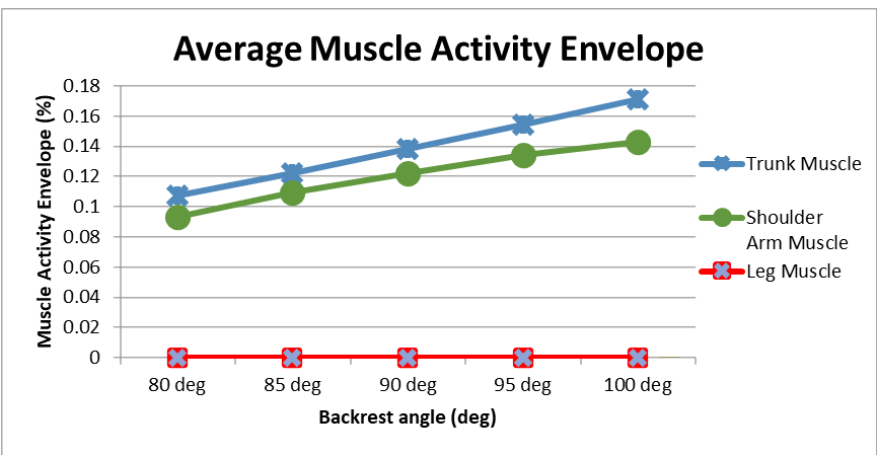

Figure 3. Average muscle activity envelope for Chair A

In the L4 to L5 graph of reaction force for Chair A (Figure 4), the trend showing an increase in reaction force resulting from increasing chair backrest angle. The reaction force was the highest at $100^{\circ}$ chair with the value of $499 \mathrm{~N}$ and the lowest was by $80^{\circ}$ chair with $336 \mathrm{~N}$. The results can be compared with the research from [17], whereby in the research it was stated that the force decreases until $20^{\circ}$ backrest angle and then increases when backrest angle is increased further as in this case the force increased continuously from $80^{\circ}$ to $100^{\circ}$ backrest angle. However, this opposed the reality where the backrest should support the body weight and lower the L4 to L5 reaction force. 


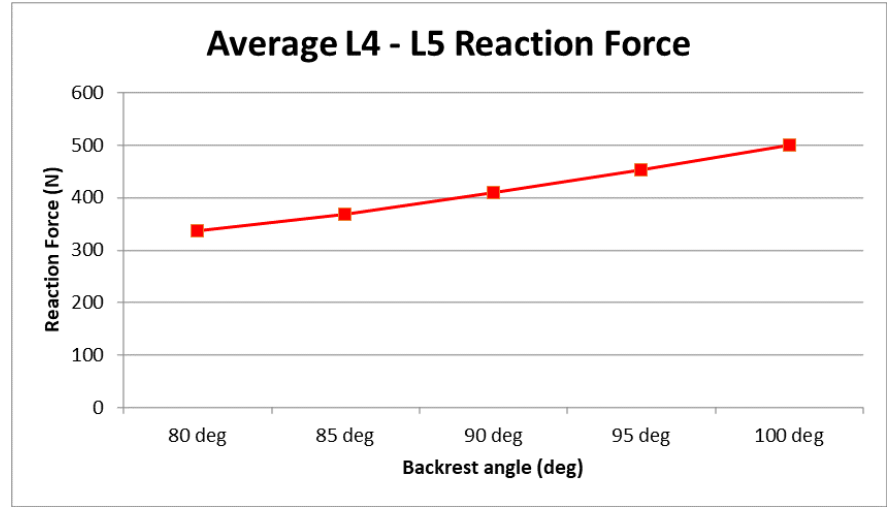

Figure 4. Average L4 and L5 reaction force of Chair A

The movement of the human model for Chair B is shown in Figure 5 below. Graph of muscle activity envelope (Figure 6) on both trunk muscle and shoulder arm muscle for Chair B are showing an approximately similar trend whereby the muscle activity envelope decreased until $0.30 \mathrm{~m}$ and increased again until $0.40 \mathrm{~m}$. From the graph, it is apparent that the lowest average trunk muscle activity envelope is $1.728 \times 10-1 \%$ by $0.30 \mathrm{~m}$ chair and the highest average trunk muscle activity envelope is by $0.40 \mathrm{~m}$ chair with $1.976 \times 10-1 \%$.
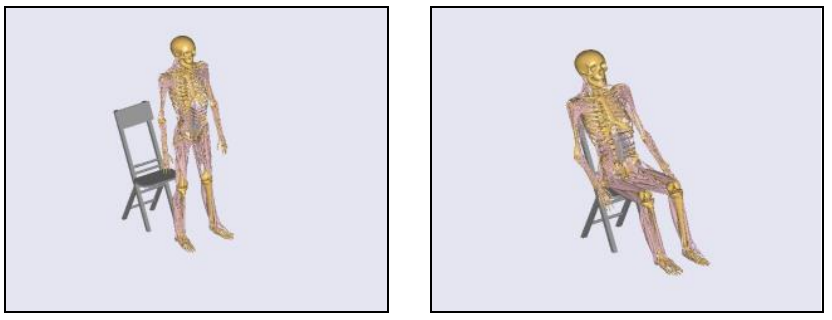

Figure 5. Initial (left) and final (right) sitting position for Chair $\mathrm{B}$

For shoulder arm muscle, the lowest average muscle activity envelope is also by $0.30 \mathrm{~m}$ chair with the value of $1.10 \times 10-1$ $\%$ while the highest by $0.40 \mathrm{~m}$ chair with $1.29 \times 10-1 \%$. Leg muscle activity envelope is the same as in Chair A as the results of the inverse dynamics analysis gives very small value. The average of L4 to L5 reaction force for Chair B shown in Figure 7. The trend of the graph is showing an increase and decrease of forces as the seat height increases.

The first simulation on $0.20 \mathrm{~m}$ chair showed a $492 \mathrm{~N}$ force on the spine. The force is lowered to about $2 \%$ when the chair seat height is increased to $0.25 \mathrm{~m}$ with the reaction force of $484 \mathrm{~N}$. The force is further decreased when the seat height is lowered to $0.30 \mathrm{~m}$ with the minimum reaction force of $466 \mathrm{~N}$. Beyond $0.30 \mathrm{~m}$ the force on the spine started to increase further. However, different human model height will have a different L4 to L5 reaction force on different seat heights. This is because different human has different level of comfort, and it depends on their physical size.

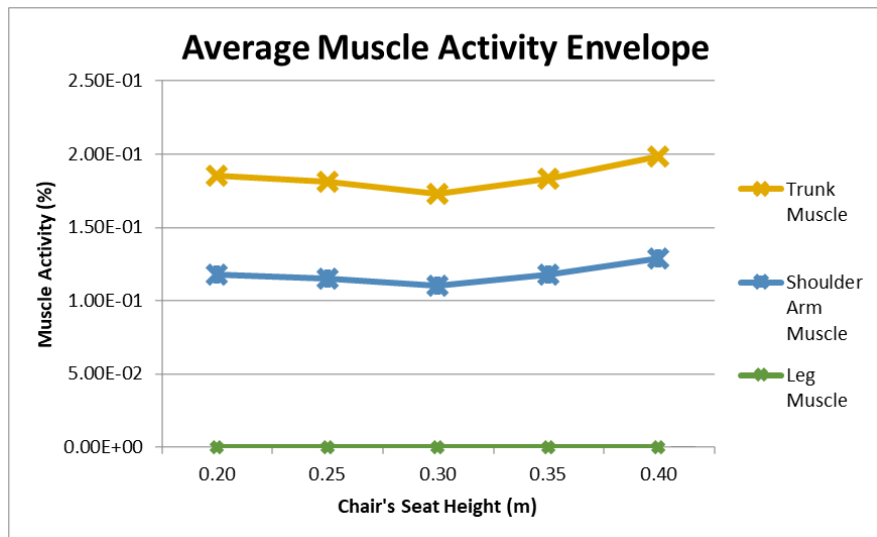

Figure 6. Average muscle activity envelope for Chair B

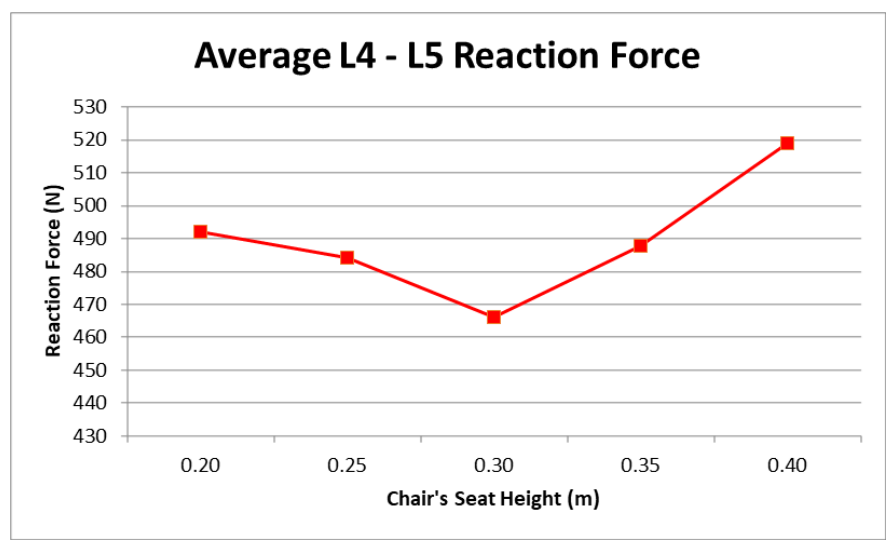

Figure 7. Average L4 and L5 reaction force for Chair B

\section{CONCLUSIONS}

The investigation was mainly focused on two aspects of chair design: backrest angle and seat height. AnyBody software was applied to conduct the simulation and analysis of two different chairs for ergonomics early intervention. Two chairs namely A and B was used as a case study for the simulation. The best ergonomic backrest angle for Chair A was $80^{\circ}$ since it gives the lowest overall trunk muscle activity and L4 to L5 reaction force of $1.37 \times 10-1 \%$ and $398 \mathrm{~N}$ respectively. The best ergonomic seat height for Chair B was $0.30 \mathrm{~m}$ as it resulted in the minimum trunk muscle activity and L4 to L5 reaction force of $1.728 \times 10-1 \%$ and $466 \mathrm{~N}$ respectively. The research shows that the simulation can be used as a tool to predict the suitable parameters for a new chair design before the real fabrication is conducted. This can benefit the creative design product that not only focusing on the 'beauty' or 'ecstatic' elements but also the effect of creative product to human health and safety. However, further work such as real-world experiment is needed to verify the simulation conducted.

\section{ACKNOWLEDGMENT}

This research is funded by UNIMAS MyRA Special Grant Schemes [Grant no: F02/SpSTG/1385/16/27]. The authors would like to thank Universiti Malaysia Sarawak (UNIMAS) for providing facilities for this research. The authors would 
like to thank Mohammad Syafiq Manaferry who supporting this project.

\section{REFERENCES}

[1] J.E. Fernandez, Ergonomics in the workplace, Facilities 13(4) (1995) 20-27.

[2] P. Stephen, Bodyspace: Anthropometry, Ergonomics and the Design of Work, CRC Press, Florida, USA, 2014, pp. $1-352$.

[3] C. Bontrup, W.R. Taylor, M. Fliesser, R. Visscher, G. Tamara, P. Wippert, R. Zemp, Low back pain and its relationship with sitting behaviour among sedentary office workers, Appl. Ergon. 81 (2019) 1-8.

[4] I. Halim, A.R. Omar, A review on health effects associated with prolonged standing in the industrial workplaces, IJRRAS 8(1) (2011) 14-21.

[5] L. McLean, M. Tingley, R.N. Scott, J. Rickards, Myoelectric signal measurement during prolonged computer terminal work, J. Electromyogr. Kinesiol. 10(1) (2000) 33-45.

[6] N.O. Oranye, B. Wallis, K. Roer, G. Archer-Heese, Z. Aguilar, Do personal factors or types of physical tasks predict workplace injury? Workplace Health \& Saf. 64(4) (2016) 141-151.

[7] E.H. Woo, P. White, C.W. Lai, Ergonomics standards and guidelines for computer workstation design and the impact on users' health - a review, Ergon. 59(3) (2016) 464-475.

[8] A. Hedge, K. Breeuwsma, Chair design beyond gender and age, Spine 6 (2008) 7.

[9] D. Mohamad, B.M. Deros, A.R. Ismail, D.D. Darius, Development of a Malaysian anthropometric database, Conference on Manufacturing Technology and Management, (2010).

[10] M. Lengsfeld, A. Frank, D.L. Van Deursen, P. Griss, Lumbar spine curvature during office chair sitting, Med. Eng. Phys. 22(9) (200) 665-669.

[11] R.S. Goonetilleke, S. Feizhou, A methodology to determine the optimum seat depth, Int. J. Ind. Ergon. 27(4) (2001) 207-217.

[12]L. Groenesteijn, P. Liesbeth, Vink, M. De Looze, F. Krause, Effects of differences in office chair controls, seat and backrest angle design in relation to tasks, Appl. Ergon. 40(3) (2009) 362-370.

[13] C.R. Mehta, L.P. Gite, S.C. Pharade, J. Majumder, M.M. Pandey, Review of anthropometric considerations for tractor seat design, Int. J. Ind. Ergon. 38(5-6) (2008) 546554.

[14] R. Alojado, Rosanna, B. Custodio, K.M. Lasala, P.L. Marigomen, Designing an ergonomic chair for pedicurists and manicurists in Quezon City, Philippines, Procedia Manuf. 3 (2015) 1812-1816.

[15] J. Rasmussen, M. Damsgaard, E. Surma, S.T. Christensen, M.D. Zee, V. Vondrak, Anybody - A software system for ergonomic optimization, Fifth World Congress on Structural and Multidisciplinary Optimization 4 (2003) 6.

[16] K. Karuppiah, M.S. Salit, M.Y. Ismail, N. Ismail, S.B. Mohd Tamrin, K. Gobalakrishnan, S. Palanimuthu, T.
Palaniandy, Anthropometry of Malaysian young adults, J. Hum. Ergol. 40(1-2) (2011) 37-46.

[17] N.A.A. Majid, M.F.E. Abdullah, M.S. Jamaludin, M. Notomi, J. Rasmussen, Musculoskeletal analysis of driving fatigue: The influence of seat adjustments, Adv. Electron. Forum. 10 (2013) 373-378.

Shahrol Mohamaddan is an Associate Professor at the Faculty of Engineering, Universiti Malaysia Sarawak (UNIMAS), Malaysia. He is currently seconded at the College of Systems Engineering and Science, Shibaura Institute of Technology, Japan. His research interest is in Ergonomics and Biomedical engineering.

Aliff Rahman is a $\mathrm{PhD}$ candidate at the Universiti Malaysia Sarawak (UNIMAS), Malaysia. He received his Bachelor and Master of Engineering from the Department of Mechanical and Manufacturing, Faculty of Engineering, UNIMAS, Malaysia. His current research focusing on Robotics and Ergonomics.

Musdi Shanat is an Associate Professor at the Faculty of Applied and Creative Arts, UNIMAS, Malaysia. His research interest is in Industrial Design and Furniture Design.

Siti Zawiah Md Dawal is an Associate Professor at the Faculty of Engineering, University of Malaya, Malaysia. Her research interest is in Ergonomics.

Akihiko Hanafusa is a Professor at the Department of Bioscience and Engineering, College of Systems Engineering and Science, Shibaura Institute of Technology, Japan. His research interest is in Biomedical engineering.

\section{Contribution of Individual Authors to the Creation of a Scientific Article (Ghostwriting Policy)}

Shahrol Mohamaddan write-up the paper, analysed the simulation and secured the grant

Aliff Rahman improved the simulation

Musdi Shanat provided the problem statement related to the chair design

Siti Zawiah Md Dawal shared the ergonomics input

Akihiko Hanafusa commented and shared expert view on human simulation

\section{Sources of Funding for Research Presented in a Scientific Article or Scientific Article Itself}

This research is funded by UNIMAS MyRA Special Grant Schemes [Grant no: F02/SpSTG/1385/16/27].

\section{Creative Commons Attribution License $\mathbf{4 . 0}$ (Attribution 4.0 International, CC BY 4.0)}

This article is published under the terms of the Creative Commons Attribution License 4.0

https://creativecommons.org/licenses/by/4.0/deed.en_US 